\title{
Ticagrelor Use in Indian Patients Undergoing Neuroendovas- cular Procedures: A Single Center Experience
}

\author{
Vivek Karan, DM, FNVI*, Devashish Vyas, DNB, FNVI*, Vikram Bohra, DM, FNVI, \\ Vikram Huded, DM, FINR \\ Division of Stroke and Interventional Neurology, NH Institute of Neurosciences, Bangalore, India
}

Purpose: A safe and efficacious antiplatelet drug is needed for patients with clopidogrel resistance who undergo neuroendovascular procedures. Ticagrelor is a new reversibly binding, oral, direct-acting P2Y receptor antagonist with no known resistance. We describe our clinical experience using ticagrelor for neuroendovascular procedures in Indian patients with clopidogrel resistance at the NH Institute of Neurosciences, Narayana Health City, Bangalore.

Materials and Methods: We retrospectively reviewed our endovascular procedure database for all patients with predefined clopidogrel resistance. Clopidogrel resistance was defined as P2Y12 inhibition $<40 \%$. Patients were administered ticagrelor along with aspirin prior to the procedure.

Results: Of 127 patients, 32 (25\%) were non-responders to clopidogrel (22 [69\%] males, 10 [31\%] females; median age, 54 years [range, 20-75]). All patients were treated with a 180-mg loading dose of ticagrelor, followed by $90 \mathrm{mg}$ twice daily. Twenty patients (63\%) underwent endovascular intervention for intracranial aneurysm, two (6\%) for dissecting aneurysms, nine (28\%) for stenotic lesions, and one (3\%) for carotico-cavernous fistula. No patient experienced any adverse effects related to the use of Ticagrelor in the postoperative period.

Conclusion: Ticagrelor is an effective alternative to clopidogrel for use in conjunction with aspirin in patients with clopidogrel resistance. None of our patients had adverse effects from ticagrelor. Drug cost, twice-daily dosing, and risk of faster platelet aggregation activation after discontinuation should be taken into consideration prior to its use in such patients.

Key Words: Clopidogrel; Ticagrelor; Endovascular procedures; Stents

\section{INTRODUCTION}

New advances in intracranial or extracranial stents, stent grafts, flow diverters, and pCONUS have changed the way in which patients are treated in the field of neurointervention. The endovascular use of these devices requires dual antiplatelet therapy due to the inherent risk of platelet-rich in-stent thrombus for- mation. ${ }^{1-3}$ The importance of dual antiplatelet therapy with aspirin and a P2Y12 receptor antagonist (such as clopidogrel, prasugrel, or ticagrelor) during stenting has been documented in numerous studies. ${ }^{4-6}$ The combination of aspirin and clopidogrel has been documented to be safe and efficacious as compared to other antiplatelet combinations. ${ }^{7-10}$ While aspirin resistance is less common,

\section{Correspondence to:}

Vikram Huded, DM, FINR

Division of Stroke and Interventional Neurology, NH Institute of Neurosciences, 258/A, Bommasandra Industrial Area, Anekal Taluk, Hosur Road, Bangalore, Karnataka 560099, India Tel: +91-9900002101

Fax: $+91-8027832648$

E-mail:drvikramhuded@gmail.com

Received: April 20, 2019

Revised: May 28, 2019

Accepted: June 27, 2019

*These authors contributed equally to the manuscript as first author.
Copyright $\odot 2019$ Korean Society of Interventional Neuroradiology This is an Open Access article distributed under the terms of the Creative Commons Attribution Non-Commercial License (http://creativecommons.org/licenses/by-nc/3.0) which permits unrestricted non-commercial use, distribution, and reproduction in any medium, provided the original work is properly cited.

pISSN 2093-9043 eISSN 2233-6273 
clopidogrel resistance may be more challenging, as it is reported to be as high as $30-35 \%$ and is reported to increase thromboembolic complications, even with escalating dosing of clopidogrel. ${ }^{11-14}$

In recent years, a few studies on patients after neurovascular stent placement have revealed similar rates of resistance for aspirin and clopidogrel compared with rates in the cardiovascular literature. ${ }^{13,15-17}$ This necessitates the need to look for a safe and efficacious antiplatelet regimen that not only minimizes the risk of neurosurgical thromboembolism after stenting but also reduces risk of perioperative intracranial hemorrhage due to potent $\mathrm{P} 2 \mathrm{Y} 12$ receptor over-inhibition.

Unlike clopidogrel, ticagrelor is a reversible allosteric binder that does not need hepatic activation. Ticagrelor and its equipotent metabolite are absorbed quickly and reach peak concentration after about 1.5 hours. ${ }^{18}$ Moreover, the extremely low number of non-responders makes it particularly advantageous for neurological stenting procedures. ${ }^{19-22}$

The purpose of this paper is to present our experience using ticagrelor in combination with aspirin in a limited cohort of Indian patients with clopidogrel resistance who underwent elective neuroendovascular procedures at the $\mathrm{NH}$ Institute of Neurosciences (Narayana Health City, Bangalore).

\section{MATERIALS AND METHODS}

\section{Study design}

All the patients undergoing intracranial or extracranial neuroendovascular stenting at the $\mathrm{NH}$ Institute of Neurosciences received a loading and maintenance antiplatelet drug dose as per a predefined medication regimen. Patients got tested for aspirin and clopidogrel resistance using light aggregometry and underwent follow-up neurovascular imaging with cerebral angiography at the end of 3 months. Their clinical, procedural, and follow-up data were prospectively collected and entered into a neurointervention procedure database.

The present retrospective study was conducted with approval by the Institutional Ethics Committee of NH Institute of Neurosciences, Narayana Health City, Bangalore. We screened our database for the period from July 2015 to March 2017, and all patients with documented clopidogrel resistance who were then shifted to a ticagrelor and aspirin regimen were included in the study. Detailed information was collected, including clinical assessment, indication for stent placement, procedural information, light aggregometry results, complications and adverse events during admission and follow up, follow-up neuroimaging results, and duration of ticagrelor therapy. Of these, patients lost to follow up or with incomplete clopidogrel test results were excluded from the analysis.

Complications that were monitored and documented in the database included 30-day thromboembolic events (stroke or myocardial infarction) and bleeding. Bleeding events were classified as per the A Randomised, Double-blind, Parallel Group, Phase 3, Efficacy and Safety Study of Ticagrelor Compared With Clopidogrel for Prevention of Vascular Events in Patients With Non-ST or ST Elevation Acute Coronary Syndromes (PLATO- a Study of PLATelet Inhibition and Patient Outcomes) trial criteria into major life-threatening, other major bleeding, and minor bleeding. ${ }^{23}$ Patients were also monitored for dyspnea, bradyarrhythmias, diarrhea, and diarrhea and increase in serum creatinine.

\section{Medication protocol}

All patients undergoing intracranial or extracranial neuroendovascular stenting at the $\mathrm{NH}$ Institute of Neurosciences received either a loading dose of $300 \mathrm{mg}$ clopidogrel and 325 mg aspirin 1 day prior to the procedure or $75 \mathrm{mg}$ clopidogrel and $150 \mathrm{mg}$ aspirin daily for 7 days before the procedure. All patients were subjected to a light transmission aggregometry test; and if it was found that they were non-responders to clopidogrel, they were started on a loading dose of 180 mg ticagrelor orally, followed by a maintenance dose of 90 mg twice daily. These patients also received heparin anticoagulation during the procedure with an activated clotting time maintained above 250 seconds for the duration of the procedure. All patients received ticagrelor for a period of 3 months.

\section{Platelet function testing}

At the NH Institute of Neurosciences, aggregation studies were done with a platelet aggregometer using a light aggregometry technique after 6 hours of a loading dose or after 7 days of antiplatelet treatment in elective cases. Non-responders were defined as those with $<40 \%$ reduction in platelet aggregation inhibition, as per the parameters observed by our institutional laboratory.

\section{Statistical analysis}

Descriptive statistical analysis was done using IBM SPSS Statistics for Windows, version 22.0 (IBM Corp, Armonk, NY, USA) 
and results were summarized as mean and median for continuous data and as proportion for frequency data.

\section{RESULTS}

From July 2015 to May 2017, of the total 127 patients who underwent a neuroendovascular procedure, 32 patients (25\%) were identified as non-responders to clopidogrel and were started on a ticagrelor and aspirin regimen. There were 22 men (69\%) and 10 women (31\%), with a median age of 54 years (range, 20-75). All procedures were elective. Twenty patients (63\%) underwent endovascular intervention for intracranial aneurysm (three bled and 17 unbled), two (6\%) for dissecting aneurysms, nine (28\%) patients for stenotic lesions, and one (3\%) patient for carotico-cavernous fistula (CCF). Of the 20 patients with aneurysms, 11 patients (55\%) were treated with flow diverters and nine patients (45\%) had stent-assisted coiling. All stenotic lesions were stented, and CCF lesions underwent stent grafting. These results are summarized in Tables 1, 2.

There were no thromboembolic phenomena (stroke or myocardial infarction) during follow up. There was no incidence of major, minor, or life-threatening bleeding. No patient had dyspnea, diarrhea, dizziness, bradyarrhythmia, or increased serum creatinine. Follow-up angiography revealed

Table 1. Clinical characteristics of clopidogrel non-responders for the neuroendovascular procedure

\begin{tabular}{lc}
\hline Variable & Value \\
\hline Total number of patients & 32 \\
Sex & $22(69)$ \\
Male & $10(31)$ \\
Female & \\
Age (years) & 54 \\
Median & $20-75$ \\
Range & \\
Age distribution (years) & 2 \\
$20-29$ & 2 \\
$30-39$ & 7 \\
$40-49$ & 13 \\
$50-59$ & 7 \\
$60-69$ & 1 \\
$>70$ &
\end{tabular}

Values are presented as number (\%). no in-stent thrombosis or stenosis

\section{DISCUSSION}

A clopidogrel and aspirin dual antiplatelet regimen has been routinely used for coronary intervention, and off-label use of this drug combination has been standard for neuroendovascular procedures. Because of the complex pathophysiology of cerebrovascular thromboembolic events involving thrombosis, inflammation, vascular biology, and hemodynamics, no single agent can be expected to completely stop ischemic events.

Clopidogrel resistance is defined as the failure of a molecule to inhibit the target of its action; it has been observed in approximately one-third of patients. It is best demonstrated by the evidence of residual post treatment P2Y12 activity by

Table 2. Neuroendovascular procedures carried out in clopidogrel non-responders after ticagrelor administration

\begin{tabular}{|c|c|}
\hline Variable & Value \\
\hline \multicolumn{2}{|l|}{ Type of procedure } \\
\hline Elective & $32(100)$ \\
\hline \multicolumn{2}{|l|}{ Indication for procedure } \\
\hline Aneurysm & $20(63)$ \\
\hline Paraophthalmic ICA & 7 \\
\hline Supraclinoid ICA & 6 \\
\hline Cavernous ICA & 2 \\
\hline Middle cerebral artery & 3 \\
\hline Anterior cerebral artery & 1 \\
\hline Vertebral artery & 1 \\
\hline Dissecting aneurysms & $2(6)$ \\
\hline Arterial stenosis & $9(28)$ \\
\hline Carotico-cavernous fistula & $1(3)$ \\
\hline Type of aneurysmal procedure & 20 \\
\hline Flow diverter & $11(55)$ \\
\hline Pipeline Embolisation Device & 1 \\
\hline p64 & 7 \\
\hline Silk & 2 \\
\hline XCalibur & 1 \\
\hline Stent assisted coiling & $9(45)$ \\
\hline Solitaire $A B$ & 6 \\
\hline Leo+ & 3 \\
\hline
\end{tabular}

Values are presented as number (\%).

ICA, internal carotid artery. 
measuring adenosine diphosphate (ADP)-induced platelet aggregation before and after treatment. No single receptor signalling pathway is responsible for its activity. Therefore, a single treatment strategy may not be sufficient to overcome clopidogrel resistance. ${ }^{24} \mathrm{~A}$ limited number of studies on clopidogrel resistance in India have been carried out on patients with acute coronary syndrome and coronary artery disease; they indicate that prevalence of clopidogrel resistance in India is aligned with the global incidence. ${ }^{25,26}$ Observational studies from the cardiovascular literature have demonstrated a relationship between clopidogrel resistance and the development of cardiovascular events after percutaneous coronary intervention. ${ }^{27,28}$ Fifi et al. ${ }^{11}$ reported increased peri-procedural thromboembolic complications from neurovascular stent-placement procedures in their patients with clopidogrel resistance.

Ticagrelor is the first reversibly binding, oral, direct-acting P2Y receptor antagonist. Clinical pharmacology and early dose-finding studies have suggested a faster onset and greater inhibition of platelet aggregation with ticagrelor than with clopidogrel. ${ }^{29,30}$ In the ONSET-OFFSET trial, ticagrelor achieved a rapid and better platelet inhibition compared to clopidogrel. ${ }^{31}$ Unlike clopidogrel, ticagrelor and its metabolite are primarily metabolized via the CYP34A enzyme and, hence, do not require hepatic activation. Also, the extremely low number of non-responders makes it particularly advantageous for neurological stenting procedures. ${ }^{19-22}$ In the PLATO trial and its sub-analyses, use of ticagrelor achieved platelet inhibition in almost all cases of clopidogrel resistance, had lower incidences of in-stent thrombosis, and had similar rates of major and fatal bleeding. ${ }^{32-34}$ However, there is limited data documenting the use of ticagrelor in patients undergoing neurointerventional procedures. Hanel et al. ${ }^{35}$ documented the safety and efficacy of ticagrelor when used in conjunction with aspirin as a dual treatment in their patients with clopidogrel resistance.

We present our experience using ticagrelor in Indian patients undergoing neurointerventional procedures who were non-responders to clopidogrel. At the NH Institute of Neurosciences, we have seen a few in-stent thromboses arise from aspirin and clopidogrel dual antiplatelet therapy. Since we started testing patients for clopidogrel resistance and moved non-responders to ticagrelor in conjunction with aspirin, we have not encountered any complications to date. All our patients tolerated ticagrelor well with no incidence of any adverse event including hemorrhage. Our study is, however, limited by having a small number of patients and a retrospective nature. A future prospective, randomized, and larger patient population study is warranted to support the safety of ticagrelor in neurointerventional procedures, especially as newer technology with interventional devices is evolving so quickly.

\section{CONCLUSION}

In summary, we report the safety and efficacy of ticagrelor when used in conjunction with aspirin in a small group of Indian patients who were non-responders to clopidogrel for neuroendovascular procedures at our center. The drawbacks of ticagrelor, including its cost and its risk of faster platelet aggregation activation after discontinuation, should be taken into consideration prior to its utilization.

\section{REFERENCES}

1. Higo T, Ueda Y, Matsuo K, Nishio M, Hirata A, Asai M, et al. Risk of in-stent thrombus formation at one year after drug-eluting stent implantation. Thromb Res 2011;128:431-434

2. Hara M, Nishino M, Taniike M, Makino N, Kato H, Egami Y, et al. High incidence of thrombus formation at 18 months after paclitaxel-eluting stent implantation: angioscopic comparison with sirolimus-eluting stent. Am Heart J 2010;159:905-910

3. Otake H, Shite J, Ako J, Shinke T, Tanino Y, Ogasawara D, et al. Local determinants of thrombus formation following sirolimus-eluting stent implantation assessed by optical coherence tomography. JACC Cardiovasc Interv 2009;2:459-466

4. Kuijpers MJE, Megens RT, Nikookhesal E, Feijge MA, De Mey $J G$, oude Egbrink MG, et al. Role of newly formed platelets in thrombus formation in rat after clopidogrel treatment: comparison to the reversible binding $\mathrm{P}_{2} \mathrm{Y}_{12}$ antagonist ticagrelor. Thromb Haemost 2011;106:1179-1188

5. Patil SB, Jackman LE, Francis SE, Judge HM, Nylander S, Storey RF. Ticagrelor effectively and reversibly blocks murine platelet P2Y12-mediated thrombosis and demonstrates a requirement for sustained P2Y12 inhibition to prevent subsequent neointima. Arterioscler Thromb Vasc Biol 2010;30:2385-2391

6. Birkeland K, Parra D, Rosenstein R. Antiplatelet therapy in acute coronary syndromes: focus on ticagrelor. J Blood Med 2010;1:197-219

7. Heer T, Juenger C, Gitt AK, Bauer T, Towae F, Zahn R, et al. Effica- 


\section{Karan V et al. Experience with Ticagrelor in Neurointerventional Procedures}

cy and safety of optimized antithrombotic therapy with aspirin, clopidogrel and enoxaparin in patients with non-ST segment elevation acute coronary syndromes in clinical practice. J Thromb Thrombolysis 2009;28:325-332

8. Sprigg N, Gray LJ, England T, Willmot MR, Zhao L, Sare GM, et al. A randomised controlled trial of triple antiplatelet therapy (aspirin, clopidogrel and dipyridamole) in the secondary prevention of stroke: safety, tolerability and feasibility. PLoS One 2008;3:e2852

9. Bowry AD, Brookhart MA, Choudhry NK. Meta-analysis of the efficacy and safety of clopidogrel plus aspirin as compared to antiplatelet monotherapy for the prevention of vascular events. Am J Cardio/ 2008;101:960-966

10. Cooke GE, Goldschmidt-Clermont PJ. The safety and efficacy of aspirin and clopidogrel as a combination treatment in patients with coronary heart disease. Expert Opin Drug Saf 2006;5:815826

11. Fifi JT, Brockington C, Narang J, Leesch W, Ewing SL, Bennet H, et al. Clopidogrel resistance is associated with thromboembolic complications in patients undergoing neurovascular stenting. AJNR Am J Neuroradiol 2013;34:716-720

12. Goh C, Churilov L, Mitchell P, Dowling R, Yan B. Clopidogrel hyper-response and bleeding risk in neurointerventional procedures. AJNR Am J Neuroradiol 2013;34:721-726

13. Prabhakaran S, Wells KR, Lee VH, Flaherty CA, Lopes DK. Prevalence and risk factors for aspirin and clopidogrel resistance in cerebrovascular stenting. AJNR Am J Neuroradiol 2008;29:281285

14. Sorkin GC, Dumont TM, Wach MM, Eller JL, Mokin M, Natarajan SK, et al. Carotid artery stenting outcomes: do they correlate with antiplatelet response assays? J Neurointerventional Surg 2014;6:373-378

15. Lee DH, Arat A, Morsi H, Shaltoni H, Harris JR, Mawad ME. Dual antiplatelet therapy monitoring for neurointerventional procedures using a point-of-care platelet function test: a single-center experience. AJNR Am J Neuroradio/ 2008;29:1389-1394

16. Müller-Schunk S, Linn J, Peters N, Spannagl M, Deisenberg M, Brückmann $\mathrm{H}$, et al. Monitoring of clopidogrel-related platelet inhibition: correlation of nonresponse with clinical outcome in supra-aortic stenting. AJNR Am J Neuroradiol 2008;29:786-791

17. Drazin D, Choulakian A, Nuño M, Kornbluth P, Alexander MJ. Body weight: a risk factor for subtherapeutic antithrombotic therapy in neurovascular stenting. J Neurointerventional Surg 2011:3:177-181

18. Cannon CP, Harrington RA, James S, Ardissino D, Becker RC, Emanuelsson $\mathrm{H}$, et al. Comparison of ticagrelor with clopidogrel in patients with a planned invasive strategy for acute coronary syndromes (PLATO): a randomised double-blind study. Lancet 2010;375:283-293

19. Capodanno D, Calvi V, Tamburino C. Effect size of ticagrelor over clopidogrel in the Platelet Inhibition and Patient Outcomes (PLATO) trial: from statistics to clinical judgment. J Cardiovasc Med (Hagerstown) 2012;13:162-163

20. Capodanno D, Dharmashankar K, Angiolillo DJ. Mechanism of action and clinical development of ticagrelor, a novel platelet ADP P2Y12 receptor antagonist. Expert Rev Cardiovasc Ther 2010;8:151-158

21. Cattaneo M. Ticagrelor versus clopidogrel in acute coronary syndromes. N Eng/ J Med 2009;361:2386; author reply 2387-2388

22. Cheng JW. Ticagrelor: oral reversible P2Y(12) receptor antagonist for the management of acute coronary syndromes. Clin Ther 2012;34:1209-1220

23. Wallentin L, Becker RC, Budaj A, Cannon CP, Emanuelsson H, Held C, et al. Ticagrelor versus clopidogrel in patients with acute coronary syndromes. N Engl J Med 2009;361:1045-1057

24. Angiolillo DJ, Fernandez-Ortiz A, Bernardo E, Alfonso F, Macaya C, Bass TA, et al. Variability in individual responsiveness to clopidogrel: clinical implications, management, and future perspectives. J Am Coll Cardiol 2007;49:1505-1516

25. Guha S, Sardar P, Guha P, Roy S, Mookerjee S, Chakrabarti P, et al. Dual antiplatelet drug resistance in patients with acute coronary syndrome. Indian Heart J 2009;61:68-73

26. Kar R, Meena A, Yadav BK, Yadav R, Kar SS, Saxena R. Clopidogrel resistance in North Indian patients of coronary artery disease and lack of its association with platelet ADP receptors P2Y1 and P2Y12 gene polymorphisms. Platelets 2013;24:297-302

27. Bonello L, Tantry US, Marcucci R, Blindt R, Angiolillo DJ, Becker R, et al. Consensus and future directions on the definition of high on-treatment platelet reactivity to adenosine diphosphate. $J$ Am Coll Cardiol 2010;56:919-933

28. Pinto Slottow TL, Bonello L, Gavini R, Beauzile P, Sushinsky SJ, Scheinowitz $M$, et al. Prevalence of aspirin and clopidogrel resistance among patients with and without drug-eluting stent thrombosis. Am J Cardiol 2009;104:525-530

29. Husted S, Emanuelsson H, Heptinstall S, Sandset PM, Wickens M, Peters G. Pharmacodynamics, pharmacokinetics, and safety of the oral reversible P2Y12 antagonist AZD6140 with aspirin in patients with atherosclerosis: a double-blind comparison to clopidogrel with aspirin. Eur Heart J 2006;27:1038-1047

30. Storey RF, Husted S, Harrington RA, Heptinstall S, Wilcox RG, Peters G, et al. Inhibition of platelet aggregation by AZD6140, a reversible oral $\mathrm{P} 2 \mathrm{Y} 12$ receptor antagonist, compared with 
clopidogrel in patients with acute coronary syndromes. J Am Coll Cardio/ 2007;50:1852-1856

31. Gurbel PA, Bliden KP, Butler K, Tantry US, Gesheff T, Wei C, et al. Randomized double-blind assessment of the ONSET and OFFSET of the antiplatelet effects of ticagrelor versus clopidogrel in patients with stable coronary artery disease: the ONSET/OFFSET study. Circulation 2009;120:2577-2585

32. Husted S, Boersma E. Case study: ticagrelor in PLATO and Prasugrel in TRITON-TIMI 38 and TRILOGY-ACS trials in patients with acute coronary syndromes. Am J Ther 2016;23:e1876-e1889

33. Becker RC, Bassand JP, Budaj A, Wojdyla DM, James SK, Cornel $J \mathrm{H}$, et al. Bleeding complications with the P2Y12 receptor an- tagonists clopidogrel and ticagrelor in the PLATelet inhibition and patient Outcomes (PLATO) trial. Eur Heart J 2011;32:29332944

34. Gurbel PA, Bliden KP, Butler K, Antonino MJ, Wei C, Teng R, et al. Response to ticagrelor in clopidogrel nonresponders and responders and effect of switching therapies: the RESPOND study. Circulation 2010;121:1188-1199

35. Hanel RA, Taussky P, Dixon T, Miller DA, Sapin M, Nordeen JD, et al. Safety and efficacy of ticagrelor for neuroendovascular procedures. A single center initial experience. J Neurointerv Surg 2014;6:320-322 